INEL-94/0071

\title{
Development and Calibration of an On-Line Aerosol Monitor for PHEBUS Test FPT1
}

J. E. O'Brien, W. J. Carmack, M. H Sprenger, G. C. Thurston, and J. L. Hunt

October, 1994

\section{DISCLAIMER}

This report was prepared as an account of work sponsored by an agency of the United States Government. Neither the United States Government nor any agency thereof, nor any of their employees, makes any warranty, express or implied, or assumes any legal liability or responsibility for the accuracy, completeness, or usefulness of any information, apparatus, product, or process disclosed, or represents that its use would not infringe privately owned rights. Reference herein to any specific commercial product, process, or service by trade name, trademark, manufacturer, or otherwise does not necessarily constitute or imply its endorsement, recommendation, or favoring by the United States Government or any agency thereof. The views and opinions of authors expressed herein do not necessarily state or reflect those of the United States Government or any agency thereof.

Idaho National Engineering Laboratory

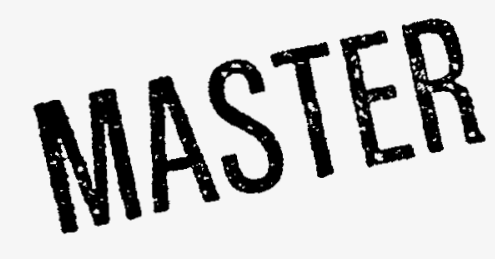

P. O. Box 1625

Idaho Falls, ID 83415 


\section{DISCLAIMER}

Portions of this document may be illegible in electronic image products. Images are produced from the best available original document. 


\begin{abstract}
An on-line aerosol monitor (OLAM2) has been developed and tested for PHEBUS test FPT1. OLAM2 utilizes new detachable fiber optic cables and sapphire light pipes for light transmission between the OLAM and the electronics. This light transmission system was tested and found to provide better signal-to-noise performance than was achieved with the continuous fibers used for test FPT0. An additional advantage of the detachable fiber/light pipe system is ease of installation. Aerosol testing (OLAM calibration) was performed in order to verify adequate signal-to-noise performance of the new fiber optic system over the specified operating conditions and to check the quantitative light attenuation measurements against theoretical predictions. Results of the testing indicated that light extinction measurements obtained during Phebus tests could be used to estimate aerosol volume concentrations, if diamond window fouling can be avoided. OLAM2 was also subjected to a proof pressure test and a long-term thermal stability test. These tests verified the mechanical and thermal integrity of the OLAM within design specifications. Long-term output signal stability was also verified with the system maintained at design temperature and half-design pressure.
\end{abstract}




\section{CONTENTS}

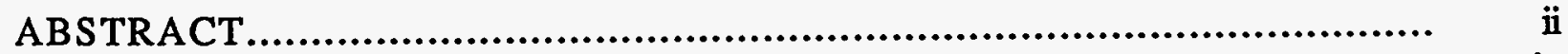

LIST OF FIGURES.............................................................. iv

LIST OF TABLES................................................................. v

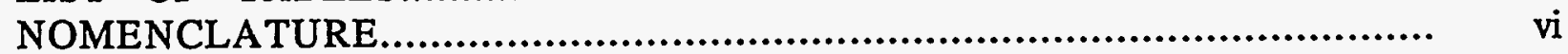

1. INTRODUCTION AND BACKGROUND.......................................... 1

2. OLAM2 DESIGN CHANGES.................................................. 1

2.1. Spool Piece Modifications................................................... 1

2.2. Fiber Optic Modifications................................................... 1

3. TEST APPARATUS AND PROCEDURE.......................................... 2

3.1. Aerosol Testing - Flow System................................................. 2

3.2. OLAM Electronics............................................................ 3

3.3. Thermal/Mechanical Integrity Testing....................................... 4

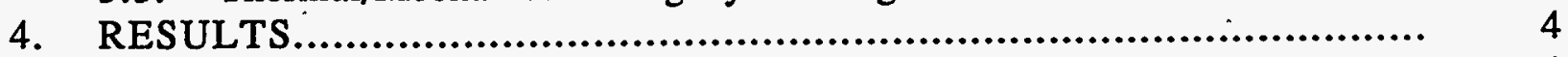

4.1. Performance of new fiber optic system...................................... 4

4.2. Aerosol test results and comparison to theoretical predictions.................... $\quad 5$

4.3. Thermal/Mechanical Integrity Testing........................................ 7

4.4. Helium Leak Tests............................................................. 9

5. SUMMARY AND CONCLUSIONS........................................... 9

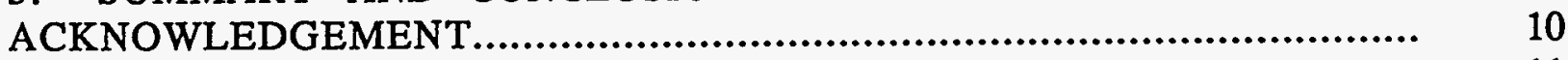

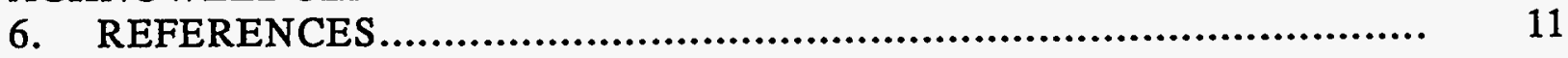




\section{FIGURES}

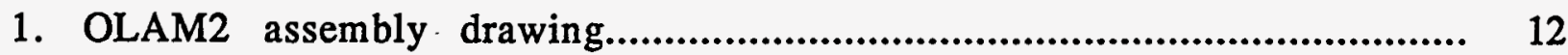

2. Scale drawing of light pipe probe with sleeve..................................................... 13

3. Photograph of light pipe probe with sleeve....................................................... 14

4. Light pipe probe without sleeve.............................................................. 15

5. Detail of light pipe ferrule........................................................................ 16

6. Schematic of OLAM aerosol test facility...................................................... 17

7. Photograph of OLAM aerosol test facility...................................................... 18

8. Photograph of aerosol generator chamber....................................................... 19

9. Schematic of OLAM electronics.................................................................. 20

10. Schematic of thermal/mechanical integrity test setup............................................ 21

11. Photograph of thermal/mechanical integrity test setup......................................... 22

12. Representative OLAM response, zinc oxide test............................................... 23

13. Log probability plot of particle size distribution................................................... 24

14. OLAM calibration data, $3 \mathrm{~cm}$ path length................................................. 25

15. OLAM calibration data, $1 \mathrm{~cm}$ path length...................................................... 26

16. OLAM temperature and pressure histories, thermal/mechanical stability test............... 27

17. OLAM output signal history, thermal/mechanical stability test................................ 28 


\section{TABLES}

1. Representative cascade impactor/diffusion battery data......................................... 6

2. Aerosol test data summary................................................................ 7 


\section{NOMENCLATURE}

\begin{tabular}{|c|c|}
\hline$d_{\mathrm{p}}$ & particle diameter, $\mu \mathrm{m}$ \\
\hline $\mathrm{d}_{50 \%}$ & particle geometric mass mean diameter, $\mu \mathrm{m}$ \\
\hline $\mathrm{d}_{84 \%}$ & 84th percentile particle diameter, $\mu \mathrm{m}$ \\
\hline I & measured light intensity, $\mathrm{W} / \mathrm{m}^{2} \mathrm{sr}$ \\
\hline$I_{0}$ & initial measured light intensity, $\mathrm{W} / \mathrm{m}^{2} \mathrm{sr}$ \\
\hline $\mathrm{L}$ & light path length, $\mathrm{m}$ \\
\hline $\mathrm{m}$ & index of refraction \\
\hline $\mathrm{m}_{\mathrm{p}}$ & total aerosol mass \\
\hline MO & curve fit intercept value \\
\hline M1 & curve fit slope value \\
\hline norm & normal distribution function \\
\hline$Q_{\text {air }}$ & air volume flow rate, $\mathrm{m}^{3} / \mathrm{s}$ \\
\hline $\mathrm{t}$ & test time, $s$ \\
\hline VC & Particle volume concentration, $\mathrm{cm}^{3} / \mathrm{m}^{3}$ \\
\hline $\mathrm{X}$ & curve fit abscissa value \\
\hline $\mathbf{Y}$ & curve fit ordinate value \\
\hline$B_{\text {ext }}$ & extinction coefficient, $\mathrm{m}^{-1}$ \\
\hline$B^{\prime}$ ext & volume-normalized extinction coefficient, $\mathrm{m}^{-1} /\left(\mathrm{cm}^{3} / \mathrm{m}^{3}\right)$ \\
\hline 0 & aerosol mass density, $\mathrm{kg} / \mathrm{m}^{3}$ \\
\hline & geometric standard deviation \\
\hline
\end{tabular}




\section{INTRODUCTION AND BACKGROUND}

An on-line aerosol monitor (OLAM2) has been developed for the PHEBUS FP Project test FPT1. This aerosol monitor is very similar to OLAM1 which was developed for and successfully applied to PHEBUS test FPT0 in December, 1993. Design of the OLAM is based on an aerosol monitor which was originally developed for PBF tests performed at INEL [1] during the early 1980's. The aerosol monitor is designed to provide an indication of the time-dependent aerosol transport behavior during severe fuel damage tests. OLAM includes two turbidity meters, or attenuation channels, in series which measure light attenuation resulting from aerosols in the effluent stream. Optical path lengths for the two channels are $3 \mathrm{~cm}$ and $1 \mathrm{~cm}$, respectively, providing a wider dynamic range than would be achievable with a single channel. Outputs from these two channels can be used to estimate time-resolved aerosol number densities based on information on aerosol composition and size distribution obtained from cascade impactors. The OLAM has been designed to operate at high temperature $\left(700^{\circ} \mathrm{C}\right)$ and high pressure $(3.5 \mathrm{MPa})$ with a high degree of reliability since the OLAM body represents a primary boundary. Modifications and improvements which were incorporated into the development of OLAM2 are described in this report along with the calibration information.

\section{OLAM2 DESIGN CHANGES}

\subsection{Spool Piece Modifications}

Details of the mechanical design of OLAM1 for test FPT0 were presented by Sprenger and Pentecost [2]. An assembly drawing of OLAM2 is presented in Fig.1. Two minor modifications were made to the spool piece for test FPT1. The first was to increase the diameter of the viewing port hole for the 3-cm-path-length channel from $1 \mathrm{~mm}$ to $2 \mathrm{~mm}$. This change was adopted in order to decrease the chance of viewport fouling. The second modification was made in the flange face of the outer housing. An O-ring groove was machined into this face instead of the one-sided recess used in OLAM1. This change was made in order to allow for the possible usage of a flexible high temperature O-ring (e.g., silicone rubber) in place of the metal C-rings which were used previously. The metal $\mathrm{C}$-rings were chosen originally due to temperature considerations. Testing indicated, however, that the temperature at the location of the outer housing flange face would be within the limits of either VITON or silicone rubber. These modifications were based on discussions which were held at INEL in February 1994 concerning OLAM performance during test FPT0. Other recommendations agreed upon at that meeting were operational, including individual control and monitoring of the four purge gas flows, continuous monitoring of the back-fill pressure in the secondary chambers behind the diamond windows, and a horizontal installation of the OLAM.

\subsection{Fiber Optic Modifications}

Some problems were encountered during fiber installation at the PHEBUS facility for test FPT0. These problems were associated with the fact that the fibers ( $200 \mu \mathrm{m}$ quartz) were continuous and that the ends of the fibers at the OLAM were sheathed within stainless steel tubing for a length of 
about $50 \mathrm{~cm}$. Consequently, installation of the fibers in the curved $17 \mathrm{~m}$ length of conduit between the OLAM and the electronics was very difficult. The sheathed fiber ends were inflexible and there was a risk of breaking the fibers at the stress point where the sheathing ended. A detachable fiber with a coupling was therefore considered for test FPT1. Due to the large percentage losses associated with any such coupling, however, a larger diameter fiber was chosen. For the portion of the light transmission fiber to be housed inside the OLAM, a sapphire light pipe (Luxtron Accufiber) was chosen. This type of light pipe is designed for use as a close-proximity optical pyrometer for surface temperature measurements in high temperature environments up to $2200^{\circ} \mathrm{C}$. A scale drawing of the light pipe is provided in Fig. 2 and a photograph is provided in Fig. 3. The light pipe is also visible in Fig. 1, as installed in the OLAM. The light transmission portion of the assembly is single-crystal sapphire with a diameter of $1.27 \mathrm{~mm}$. Total sensor length is $25.3 \mathrm{~cm}$. At the coupling end of the light pipe, a stainless steel sleeve $(6.0 \mathrm{~mm}$ diameter; $9.652 \mathrm{~cm}$ length) surrounds the sapphire rod. The sapphire rod itself is fitted with a ferrule, shown in Figs. 4 and 5 which is designed to fit inside of a fiber optic coupler on one side and the stainless steel sleeve on the other. Inside the coupler, a butt connection is made to a flexible quartz fiber optic transmission cable (600 $\mu \mathrm{m}$ fiber diameter, $17 \mathrm{~m}$ length). Inside the stainless steel sleeve, the ferrule O-ring shown in Fig. 5 is seated on a mating surface, providing a high quality seal for either vacuum or pressure applications.

After installation, the exposed length of sapphire rod and most of the sleeve length is located inside of the OLAM spool piece housing. The sapphire rod extends into the secondary chamber behind the diamond window assembly. During initial installation, the light pipe is inserted into the spool piece through a 6-mm Swagelok fitting until the end of the light pipe actually contacts the diamond window assembly. The light pipe is then pulled out slightly (approximately $1.5 \mathrm{~mm}$ ) and the fitting is swaged at this point. No further adjustment is needed for subsequent light pipe insertions.

\section{TEST APPARATUS AND PROCEDURE}

\subsection{Aerosol Testing - Flow System}

Aerosol testing (OLAM calibration) was done at the INEL in order to verify adequate signal-tonoise performance of the new fiber optic system over the specified operating conditions and to compare this performance to that of the fiber optics used for test FPT0. A schematic of the system used for the aerosol calibration testing is shown in Fig. 6 and a photograph of the setup is provided in Fig. 7. The system included three primary components: an aerosol generator, the OLAM, and the cascade impactor/diffusion battery. Two different aerosol generators were used. For most tests, a zinc oxide aerosol was generated inside of a cylindrical stainless steel chamber (shown in Fig. 8). An electric resistance heater coil was located inside of the chamber. Several small pellets of zinc metal (Fisher Scientific 99.8\%; approximately $1 \mathrm{gm}$ of $\mathrm{Zn}$ metal was used) were placed on the heater coil and electric current was passed through the heater. A thermocouple was also positioned inside of the coil. When the indicated temperature reached about $600^{\circ} \mathrm{C}$, the zinc metal would begin to burn, producing dense zinc oxide aerosol. Aerosol was transported to the OLAM by air flow (typically $15 \mathrm{slpm}$ ) as indicated in Fig. 6 . Typical aerosol volume concentrations produced by this method were $1-2 \mathrm{~cm}^{3}$ aerosol $/ \mathrm{m}^{3}$ air. For a few of the tests, a sodium chloride aerosol was generated using a spray atomizer fed by an aqueous sodium chloride solution. 
Volume concentrations produced by this method were much lower, on the order of $0.01 \mathrm{~cm}^{3} / \mathrm{m}^{3}$. Conditions at the OLAM for these aerosol tests were essentially ambient temperature and a slightly above-ambient pressure due to the pressure drop across the impactor/diffusion battery assembly. These conditions were monitored during the tests using a thermocouple and pressure transducer as indicated in Fig. 6.

During aerosol testing, purge flows were maintained in the four active purge ports at the rate of 20 mlpm for each purge port. Argon gas was used for the purge flow rather than nitrogen, simply because it was available in the laboratory. Purge flow rates were monitored using two rotameters, each measuring half of the total purge flow rate. The purge flows were split again downstream of the two rotameters, with each identical leg receiving half of the flow.

Downstream of the OLAM, a cascade impactor/diffusion battery assembly was used to capture the aerosol and determine its size distribution. The cascade impactor (In-Tox Products 02-250;14 1/m) includes seven stages, covering the $0.8-13 \mu \mathrm{m}$ size range. The final filter of the cascade impactor was removed and particles smaller than $0.8 \mu \mathrm{m}$ entered a parallel flow diffusion battery (In-Tox 02-2000) which collects particles down to $0.1 \mu \mathrm{m}$. A nonlinear inverse algorithm [3] was used to determine the particle size distribution from the diffusion battery measurements.

Air flow rates through the main body of the OLAM were monitored continuously during aerosol testing using a Hastings Model HFM-201 thermal mass flow meter located downstream of the impactor/diffusion battery assembly.

Temperature, pressure and flow rate information were monitored continuously using an HP model $3852 \mathrm{~A}$ data acquisition/control unit which was configured for these tests with a 20-channel FET multiplexer with thermocouple compensation (HP model 44710A) and a $51 / 2$ digit integrating voltmeter (HP model 44701A). The data acquisition system was interfaced to the system controller computer via an IEEE-488 bus. An IEEE-488 interface card (National Instruments Model NBDMA 2800) was added to a Macintosh IIci computer for this purpose. Data acquisition system programming was accomplished using Labview (National Instruments Version 3.0) software.

\subsection{OLAM Electronics}

Light extinction measurements in the OLAM were made using a system including two of the sapphire light pipes and quartz fiber optic cables described earlier along with two of the old-style continuous fibers used for test FPT0. These fiber optics were interfaced to the electronics shown schematically in Fig. 9. The light source used for the extinction measurements is an infra-red LED with a wavelength of $0.841 \mu \mathrm{m}$. The transmitting fiber optic cables are connected to the LED source using a standard ST connector. The LED source requires a $12 \mathrm{~V} \mathrm{DC}$ power input and a sinusoidal input from a function generator. For the calibration tests, both LED channels were driven from a single function generator (Stanford Research Systems Model DS 345) using a voltage amplitude of $8 \mathrm{Vpp}$ and a frequency of $220 \mathrm{~Hz}$. The sinusoidal signal from the waveform generator is also fed into the phase-lock amplifiers (Stanford Research Systems Model SR 510) as a reference signal. The transmitting fiber optics supply the modulated LED light to the transmitting sapphire light pipes via the fiber optic coupler. The light then traverses the OLAM flow channel and is intercepted on the opposite side by the receiving light pipes which in turn supply this light to 
the receiving quartz fiber optic cables. The receiving fiber optic cables are connected to a photodetector. The electrical output from the photodetector is fed into the phase lock amplifiers, which provide a DC output signal proportional to the light intensity received at the reference frequency. The DC output signal was monitored continuously during testing via an IEEE-488 interface on the SR 510. A Labview program was written specifically for this purpose. The Labview program also allowed for complete remote control of the SR 510. All SR 510 settings were automatically written to each data file header as a permanent record.

\subsection{Thermal/Mechanical Integrity Testing}

A thermal/mechanical integrity test was performed on the OLAM in order to verify the design pressure (3.5 MPa) capability (proof pressure test) and to demonstrate adequate signal and system stability at design temperature $\left(700^{\circ} \mathrm{C}\right)$ and half design pressure $(1.83 \mathrm{MPa})$. A schematic of the thermal/mechanical integrity test setup is provided in Fig. 10. Available laboratory argon bottles were used instead of nitrogen for inert pressurization of both the primary and secondary chambers. The plumbing was configured to allow independent pressurization of the primary and secondary OLAM chambers and also to allow pre-heat vacuum purging of both chambers. Independent pressurization of the two chambers was required for both the proof pressure test and for the system stability test. For the heated stability test, vacuum purging of both chambers was performed prior to pressurization of the primary chamber and back-filling of the secondary chamber. For both tests, the secondary chamber was back-filled with argon to a pressure just above one atmosphere. The purge flow lines were capped for these tests since there was no primary flow and no aerosols were present. Pressures were monitored continuously during the tests using a 200 psig pressure transducer (BLH Model HMD) for the primary chamber and a 15 psia transducer (Sensotec Model TJE) for the secondary chamber.

Seven thermocouples (type $\mathrm{K}$ ) were spot-welded directly to the OLAM body at the locations indicated in Fig. 10. Outputs of six of these thermocouples (T1, T3-T7) were fed into the data acquisition system (HP3852A) described earlier. Thermocouple T2 was wired into a PID controller (OMEGA Model CN 380) which provided on/off heater control via a solid-state relay (OMEGA Model SSR240DC45) to a tape heater (OMEGA Catalog No. STH052-120). When the relay was closed, the tape heater dissipated $940 \mathrm{~W}$ using $240 \mathrm{VAC}$. Prior to heating, the tape heater was carefully wrapped around the body of the OLAM and is visible in Fig 11. In order to prevent local overheating, care was taken to avoid overlapping the tape. During heating, the high temperature central portion of the assembly was insulated with a specially fabricated insulation blanket. The same blanket was used for the thermal testing of OLAM1 [2].

\section{RESULTS}

\subsection{Performance of new fiber optic system}

An initial test objective was to compare the performance of the new sapphire light pipe/detachable fiber optic system to the performance of the old continuous-fiber system. The relevant performance criterion was the magnitude of the DC output signal obtained from the phase-lock amplifier for each system under identical conditions. This output signal is proportional to the light 
intensity at the photodetector. The sapphire light pipe/quartz fiber optic system included full-length fiber optics $(17 \mathrm{~m})$. The old continuous fibers, which were developed for the testing done on OLAM1 (developed for test FPT0), were much shorter length $(\sim 4 \mathrm{~m})$. Despite the existence of a fiber optic coupler, with its expected light attenuation (typically about $3 \mathrm{~dB}$ ), the new sapphire light pipe/quartz fiber optic system with full-length fibers provided a signal which was 2-3 times stronger than the old fiber optics, when comparing signal levels obtained from the same path length OLAM location. Signal levels for either fiber optic system obtained from the 1-cm-path-length channel were about three times larger than those obtained from the 3-cm-path-length.

\subsection{Aerosol test results and comparison to theoretical predictions}

In order to achieve the high particle number densities and attenuation levels expected during the actual PHEBUS tests, most of the aerosol tests were performed using the zinc oxide aerosol generator described in the apparatus section. With this system, estimated aerosol particle number concentrations as high as $107 / \mathrm{cc}$ were achieved, resulting in aerosol volume concentrations in the $1-2 \mathrm{~cm}^{3} / \mathrm{m}^{3}$ range. Results of a representative test are presented in Fig. 12 . In the figure, relative intensities of transmitted light are plotted for the 1-cm-path-length channel and the 3-cm-pathlength channel together. Passage of the zinc oxide aerosol is characterized by a rapid drop in transmitted light due to particle absorption and scattering. For this particular test, maximum attenuation values of approximately $8 \%$ and $22 \%$ were observed for the $1-\mathrm{cm}$ path and the $3-\mathrm{cm}$ path respectively. The signal recovers to the $100 \%$ level in both cases. Signal recovery occurs over a longer time period than the initial signal drop, reflecting the time required for the aerosols to be completely cleared from the aerosol generation chamber. Total time duration of aerosol passage for this test was about $75 \mathrm{sec}$.

For the purposes of OLAM calibration, the measured light attenuation data were used in conjunction with particle size and concentration information obtained from the cascade impactor/diffusion battery and air flow rate measurements. A representative set of these data taken from the same test for which light attenuation data were presented in Fig. 12 are presented in Table 1. Cutoff diameters were calculated for each impactor stage based on the stage geometry and the air flow rate. Mass measurements for each impactor particle size range were obtained by direct before-and-after filter measurements using an analytical balance (Mettler AE50) with a resolution of $0.1 \mathrm{mg}$. For the diffusion battery, the tabulated mass values and particle size distributions were inferred from direct mass measurements using a nonlinear inverse algorithm [3]. Volume concentrations for each size range and for the overall distribution are obtained from

$$
V C=\frac{m_{p} / \rho_{p}}{Q_{a i r} t}
$$

using a density of $1.57 \mathrm{~g} / \mathrm{cc}$ for the zinc oxide aerosol [5]. 
Table 1. Representative cascade impactor/diffusion battery data.

\begin{tabular}{|c|c|c|c|}
\hline cutoff diameter $(\mu \mathrm{m})$ & mass $(\mu \mathrm{g})$ & $\begin{array}{c}\text { volume concentration } \\
\left(\text { cc particle/m }{ }^{3} \text { air }\right)\end{array}$ & $\begin{array}{c}\text { cumulative mass } \\
\text { fraction, } \%\end{array}$ \\
\hline impactor & & & \\
\hline 12.839 & 1400 & $4.60 \mathrm{E}-02$ & 98.08 \\
\hline 8.015 & 1500 & $4.93 \mathrm{E}-02$ & 94.09 \\
\hline 5.057 & 2400 & $7.88 \mathrm{E}-02$ & 88.73 \\
\hline 3.148 & 3600 & $1.18 \mathrm{E}-01$ & 80.48 \\
\hline 1.967 & 5000 & $1.64 \mathrm{E}-01$ & 68.67 \\
\hline 1.264 & 5800 & $1.91 \mathrm{E}-01$ & 53.82 \\
\hline 0.793 & 5200 & $1.71 \mathrm{E}-01$ & 38.71 \\
\hline diffusion battery & & & 28.52 \\
\hline 0.65 & 2208.96 & $7.26 \mathrm{E}-02$ & 22.52 \\
\hline 0.46 & 2155.6 & $7.08 \mathrm{E}-02$ & 16.72 \\
\hline 0.33 & 2070.95 & $6.80 \mathrm{E}-02$ & 11.21 \\
\hline 0.23 & 1936.67 & $6.36 \mathrm{E}-02$ & 6.18 \\
\hline 0.17 & 1723.69 & $5.66 \mathrm{E}-02$ & 1.9 \\
\hline 0.12 & 1385.86 & $4.55 \mathrm{E}-02$ & \\
\hline & & & \\
\hline Totals & 36381.73 & $1.20 \mathrm{E}+00$ & \\
\hline
\end{tabular}

Particle size statistics were obtained using classical methods [6,7]. Particle size distribution data were plotted on a $\log$ probability graph, as shown in Fig. 13 for the data of Table 1. The vertical axis on this figure is the logarithm (base 10) of the particle size expressed in microns. The abscissa is the mass cumulative fraction on a log probability scale. The data fit a straight line reasonably well on these coordinates, indicating a good approximation to a log normal size distribution. Particle geometric mass mean diameter and standard deviation can be obtained directly from a straight-line curve fit of the log probability data. These statistics are shown on the figure. The value of $\log \left(\mathrm{d}_{\mathrm{p}}\right)$ at a mass cumulative fraction of $50 \%$ yields the geometric mass mean diameter, $\mathrm{d}_{50 \%}$. The ratio $\mathrm{d}_{84 \%} / \mathrm{d}_{50 \%}$ provides the geometric standard deviation, $\sigma$. For a log normal distribution, specification of the geometric mean diameter and the geometric standard deviation is sufficient to fully characterize the size distribution.

Theoretical values of light attenuation depend on the aerosol volume concentration, index of refraction, and particle size distribution. A model developed by Brockmann [8] for prediction of extinction coefficients for log normal aerosol distributions was invoked in order to provide a basis of comparison for the observed light extinction values. For specified values of index of refraction, particle geometric mean diameter, and standard deviation, estimated values of the volumenormalized extinction coefficient, $B^{\prime}$, can be obtained from the Brockmann model $[8,9]$. For the zinc oxide aerosol, an estimated index of refraction, $m$, of 2.0 was used [3]. Once the value of $B^{\prime}$ has been determined, light attenuation can be predicted from 


$$
I / I_{o}=\exp \left(-\beta^{\prime} V T L\right)
$$

where $\mathrm{L}$ is the optical path length. Experimental geometric mass mean diameters, $\mathrm{d}_{50 \%}$, and geometric standard deviation values, $\sigma$, determined for each test from $\log$ probability curve fits are presented in Table 2. Experimental values of volume concentration and light attenuation are also tabulated. Geometric mass mean diameter values ranged from 0.58 to $1.64 \mu \mathrm{m}$. Geometric standard deviation values ranged from 2.6 to 3.2. Extinction coefficients in this size range do not depend strongly on geometric standard deviation, however.

Measured light extinction data are presented in Figs. 14 and 15 for the 3-cm and $1-\mathrm{cm}$ paths, respectively. Theoretical light extinction curves for $\mathrm{m}=2.0$ and $\sigma=2.0$ are also shown on each figure for mass mean diameters of 1 and $2 \mu \mathrm{m}$. Most of the data points were obtained from the zinc oxide aerosol generator. One data point on each figure was obtained from the sodium chloride aerosol generator. As is evident from the data, the zinc oxide aerosol generator tended to produce aerosol volume concentrations near $1.5 \mathrm{~cm}^{3} / \mathrm{m}^{3}$. This aerosol concentration was found to be relatively independent of the initial mass charge of zinc metal placed on the heater coil within the aerosol generator chamber. Small zinc charges simply resulted in shorter test times, and tended to produce the same rate of aerosol production. The spray atomizer used to generate sodium chloride aerosols resulted in a maximum volume concentration near the value of 0.03 shown in Table 2 .

Agreement between measured light extinction and theory is reasonable, indicating that light extinction measurements obtained during Phebus tests could be used to estimate aerosol volume concentrations, if diamond window fouling can be avoided.

\subsection{Thermal/Mechanical Integrity Testing}

Thermal/mechanical integrity testing included a proof pressure test and a long-term thermal stability test. For the proof pressure test, the primary OLAM chamber was pressurized to full design pressure $(3.4 \mathrm{MPa})$ and isolated for 10 minutes. No evidence of leakage or other anomalies were observed.

Table 2. Aerosol test data summary.

\begin{tabular}{|c|c|c|c|c|c|}
\hline aerosol & $\mathrm{d}_{50 \%}(\mu \mathrm{m})$ & $\sigma$ & $\mathrm{VC}, \mathrm{cm}^{3} / \mathrm{m}^{3}$ & $\%$ atten, $3 \mathrm{~cm}$ & $\%$ atten, $1 \mathrm{~cm}$ \\
\hline & & & & & \\
\hline $\mathrm{ZnO}$ & 1.617 & 3.111 & 1.2917 & 20 & 8 \\
\hline $\mathrm{ZnO}$ & 1.642 & 3.353 & 2.5652 & 50 & 15 \\
\hline $\mathrm{ZnO}$ & 1.557 & .3 .672 & 5.515 & 70 & 45 \\
\hline $\mathrm{ZnO}$ & 0.76 & 3.076 & 1.3098 & 13 & 5 \\
\hline $\mathrm{ZnO}$ & 1.405 & 2.687 & 0.37734 & 4 & 2 \\
\hline $\mathrm{ZnO}$ & 1.211 & 3.263 & 1.2844 & 17.5 & 6 \\
\hline $\mathrm{ZnO}$ & 1.142 & 3.285 & 1.1937 & 20 & 7 \\
\hline $\mathrm{ZnO}$ & 0.733 & 2.687 & 2.61 & 30 & 10 \\
\hline $\mathrm{ZnO}$ & 0.578 & 2.807 & 1.38 & 15 & 8 \\
\hline $\mathrm{NaCl}$ & 0.62 & 3.211 & 0.033 & 0.274 & 0.226 \\
\hline
\end{tabular}


For the long-term thermal stability test, the central portion of the OLAM was wrapped with heater tape, insulated, and heated to $700^{\circ} \mathrm{C}$. A schematic of the system used for the long-term stability test was provided in Fig. 10. The control temperature, T2, was located at the center of the OLAM body, as shown in the schematic. This thermocouple was wired into the PID controller, and was therefore not recorded by the data acquisition system. The design temperature of $700^{\circ} \mathrm{C}$ was maintained at T2 for a thermal soak period of over three hrs. Temperatures measured at the six other locations indicated in Fig. 10 are plotted on Fig. 16 as a function of time. Temperatures T1 and T3 tracked together very close to the control temperature and reached a maximum value near $690^{\circ} \mathrm{C}$. Temperature T5, located on the inner flange of the OLAM near the radial location of the diamond windows, achieved a maximum value of $515^{\circ} \mathrm{C}$ during the thermal soak period. Temperature T6, located at the purge flow inlet location, achieved a maximum value of $264^{\circ} \mathrm{C}$ during the thermal soak period. Temperatures T4 and T7, at the outer housing flange, tracked together and achieved a maximum value of $156^{\circ} \mathrm{C}$ during the thermal soak period. The maximum outer housing flange temperature is of particular interest if silicone rubber $\mathrm{O}$-rings are used at this flange instead of metal C-rings. Silicone rubber is rated to about $230^{\circ} \mathrm{C}$ for continuous use. Assuming that the heat tracing of the OLAM which will be performed prior to test FPT1 will be similar to what was done for these thermal stability tests, the silicone rubber O-rings should perform well and will be preferable to the metal C-rings due to their better sealing performance.

Argon absolute pressures maintained inside the primary and secondary chambers during the thermal stability test are also plotted in Fig. 16. During the thermal soak period, the primary pressure was increased to $1720 \mathrm{kPa}$. The primary chamber was then isolated. Primary pressure remained constant in the isolated primary chamber during the thermal soak period and subsequently decreased in magnitude during the cool-down period according to the ideal gas law. Absolute argon pressure in the secondary chamber was maintained at $109 \mathrm{kPa}$ for the entire duration of the test via a pressure regulator. Local barometric pressure in the laboratory during the thermal stability test was approximately $84 \mathrm{kPa}$.

A time history of the DC output signal obtained during the thermal stability test from the SR 510 phase lock amplifier for the 3-cm path length channel is presented in Fig. 17. Sapphire light pipes and coupled light transmission fibers were installed on both the sending and receiving optics at the 3-cm path length location for the thermal stability test. The SR 510 output exhibited some instability during the initial heat-up period during which time the signal magnitude actually rose from about $12 \mathrm{mV}$ to slightly over $16 \mathrm{mV}$. This instability and signal increase may have been due to bake-out of deposits on the diamond windows. The old diamond windows were used during these tests.

After the initial heat-up period, the output signal remained stable, within $\pm 1 \%$ for over three hours. Subsequently, the output signal included some negative excursions of about $3 \%$, with the signal recovering to its pre-excursion level after each excursion. These excursions are somewhat mysterious. Signal stability will be checked again after OLAM2 installation at Cadarache. 


\subsection{Helium Leak Tests}

A helium leak test was performed in order to check the sealing integrity of the OLAM welds. The welds were checked under vacuum using a commercial helium leak detector (Balzer Model HLT 150) and found to be leak-tight to $9 \times 10^{-7} \mathrm{mbar} 1 / \mathrm{s}$. The brazed diamond window assemblies were leak-checked at the manufacturer (Omley Industries, [4]) at $700 \mathrm{psi}$ and found to be leak-tight to better than $1 \times 10^{-9} \mathrm{cc} / \mathrm{s}$.

\section{SUMMARY AND CONCLUSIONS}

An on-line aerosol monitor (OLAM2) has been developed for PHEBUS test FPT1. This aerosol monitor is very similar to OLAM1 which was developed for and successfully applied to PHEBUS test FPT0 in December, 1993. It is designed to provide an indication of the time-dependent aerosol transport behavior during severe fuel damage tests. OLAM includes two turbidity meters, or attenuation channels, in series which measure light attenuation resulting from aerosols in the effluent stream. Optical path lengths for the two channels are $3 \mathrm{~cm}$ and $1 \mathrm{~cm}$, respectively, providing a wider dynamic range than would be achievable with a single channel. Outputs from these two channels can be used to estimate time-resolved aerosol number densities based on information on aerosol composition and size distribution obtained from cascade impactors. The OLAM has been designed to operate at high temperature $\left(700^{\circ} \mathrm{C}\right)$ and high pressure $(3.5 \mathrm{MPa})$ with a high degree of reliability since the OLAM body represents a primary boundary.

OLAM2 utilizes new detachable fiber optic cables and sapphire light pipes for light transmission between the OLAM and the electronics. This light transmission system was tested and found to provide better signal-to-noise performance than was achieved with the continuous fibers used for test FPT0. An additional advantage of the detachable fiber/light pipe system is ease of installation.

Aerosol testing (OLAM calibration) was performed in order to verify adequate signal-to-noise performance of the new fiber optic system over the specified operating conditions and to check the quantitative light attenuation measurements against theoretical predictions. Results of the testing indicated that light extinction measurements obtained during Phebus tests could be used to estimate aerosol volume concentrations, if diamond window fouling can be avoided.

OLAM2 was also subjected to a proof pressure test and a long-term thermal stability test. These tests verified the mechanical and thermal integrity of the OLAM within design specifications. Long-term output signal stability was also verified with the system maintained at design temperature and half-design pressure. 


\section{ACKNOWLEDGEMENT}

This report was performed under the auspices of the Division of Systems Research, Office of Nuclear Regulatory Research, U. S. Nuclear Regulatory Commission, NRC FIN W4617, under the DOE Idaho Field Office, Contract No. DE-AC07-76ID01570. 


\section{REFERENCES}

1. Adams, J.P., Partin, J. K., Petti, D. A., and Reed, T. R., "Development and Calibration of an Aerosol Monitor Used for PBF-Test SFD 1-4," Proceedings, 4th International Symposium on Multiphase Transport and Particulate Phenomena, pp. 177-193, December, 1986.

2. Sprenger, M. H., and Pentecost, C. G., "PHEBUS On-Line Aerosol Monitor Development Test Program," INEL Technical Report EGG-NE-10145, March, 1992.

3. Kapadia, A., "Data Reduction Techniques for Aerosol Size Distribution Measuring Instruments," Ph.D. Thesis, U. of Minnesota, 1980.

4. Omley Industries Inspection Report \#1704, July, 1994.

5. Handbook of Chemistry and Physics, Vol. 60, CRC Press Inc., Boca Raton, FL, 1979.

6. Hinds, William C. Aerosol Technology Properties, Behavior, and Measurement of Airborne Particles, John Wiley and Sons. New York. 1982.

7. Stockham, John D. and Fochtman, Edward G., eds. Particle Size Analysis Ann Arbor Science Publishers Inc. Ann Arbor, Mich. 1978.

8. Brockmann, J. E., Pentecost, G., Lucero, D. A., and Romero, T., "Calibration of the On-Line Aerosol Monitor (OLAM) with Ammonium Chloride and Sodium Chloride Aerosols," Sandia Report SAND93-0046 • UC-523, December 1993.

9. Willeke, K., and Brockmann, J. E., "Extinction Coefficients for Multimodal Atmospheric Particle Size Distributions," Atmospheric Environment, Vol. 11, pp. 995-999, 1977. 


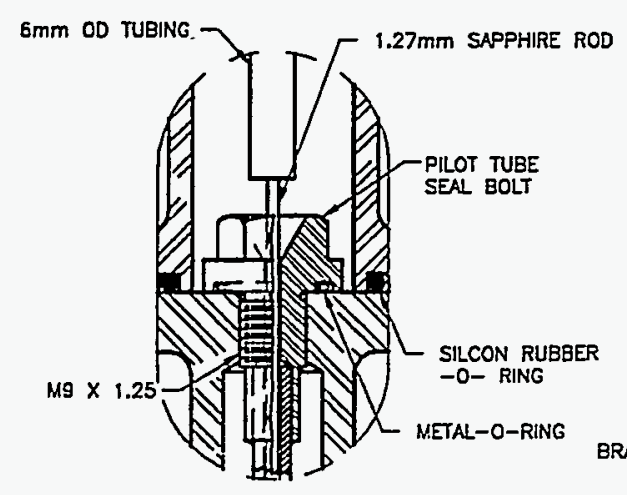

VIEW A

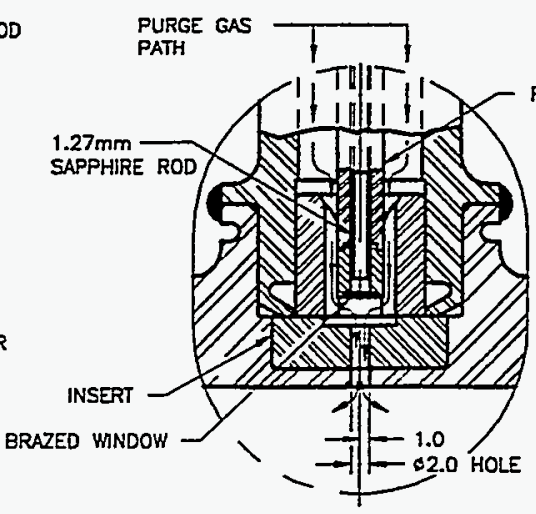

VIEW B

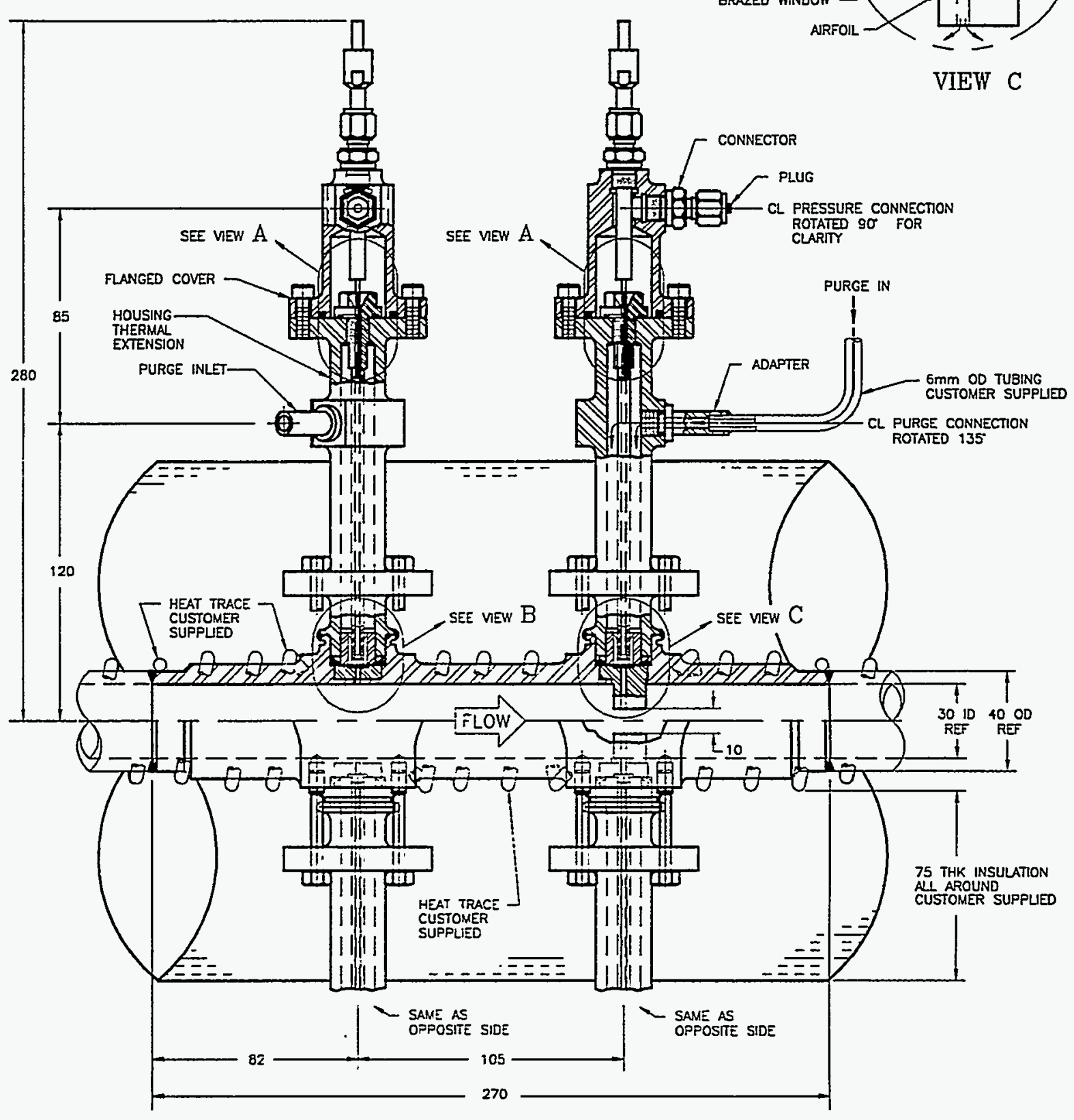

Figure 1. OLAM2 assembly drawing. 

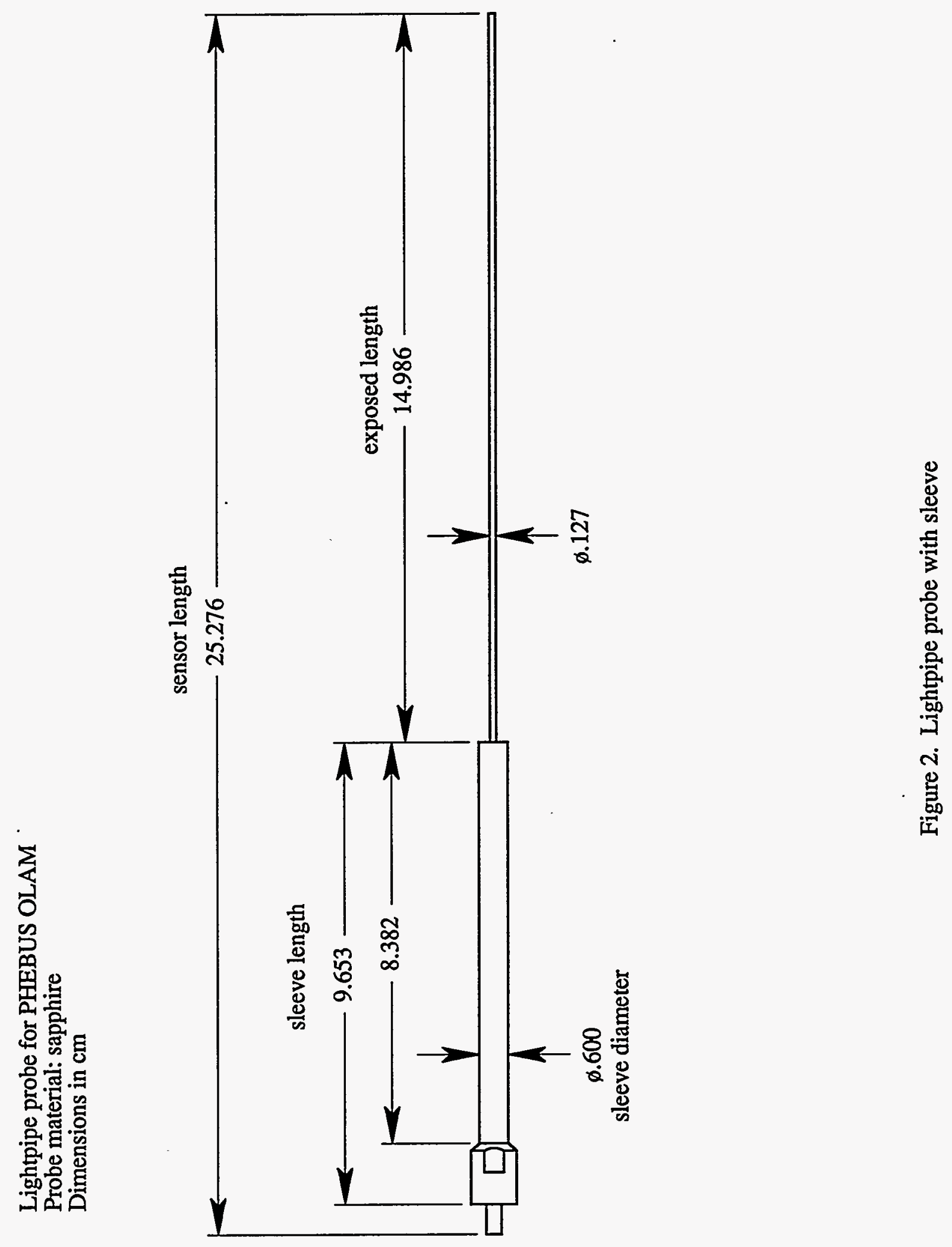

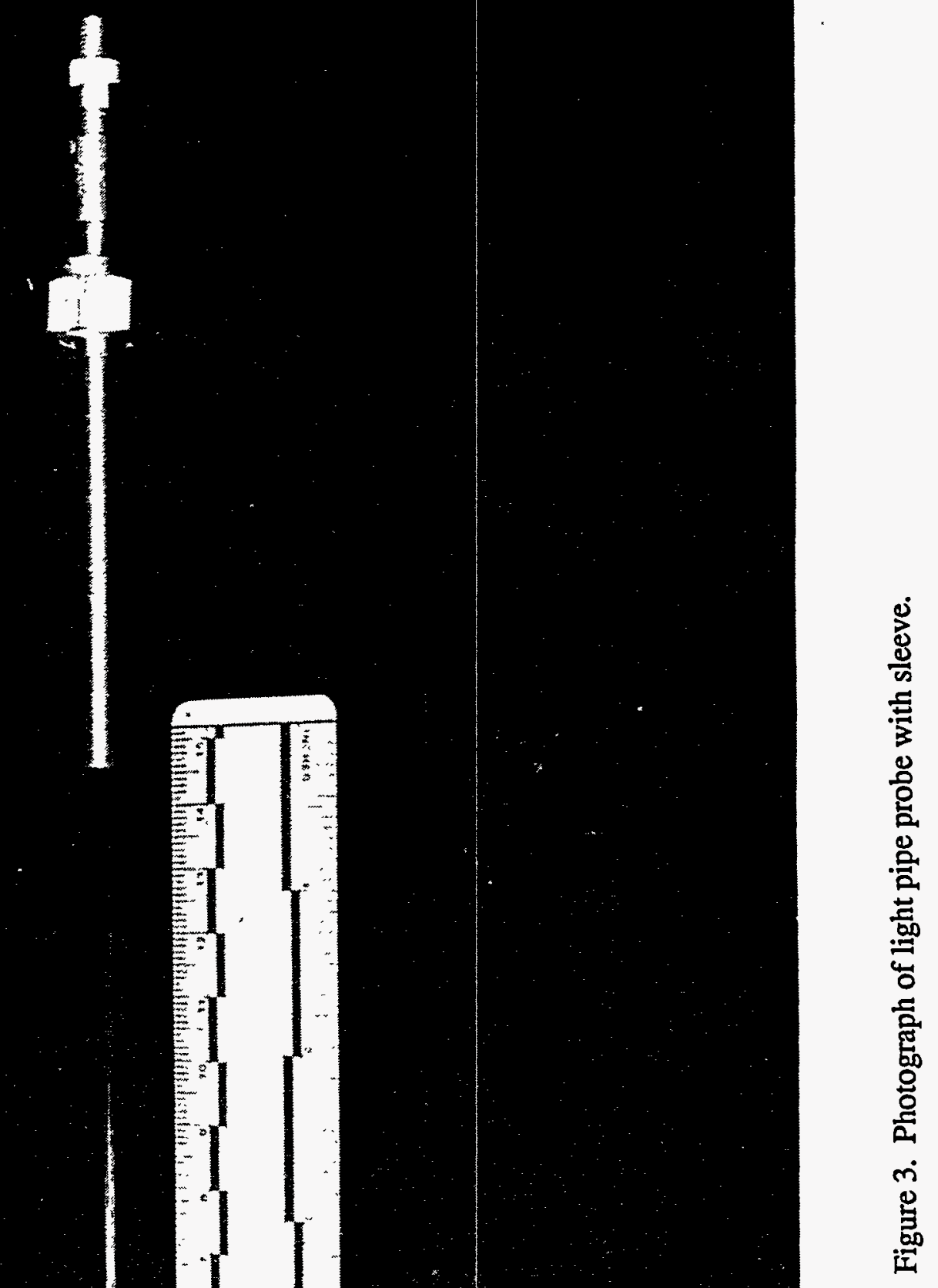

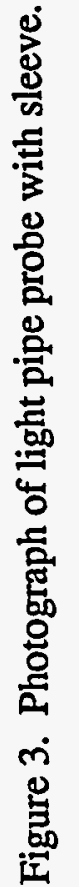


Lightpipe probe for PHEBUS OLAM

Probe material: sapphire

Dimensions in $\mathrm{cm}$

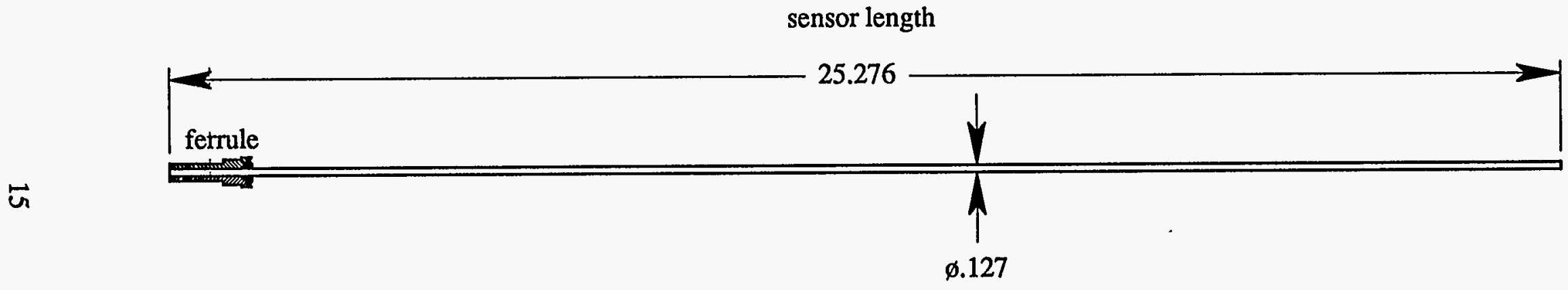

light pipe diameter

Figure 4. Lightpipe probe without sleeve. 


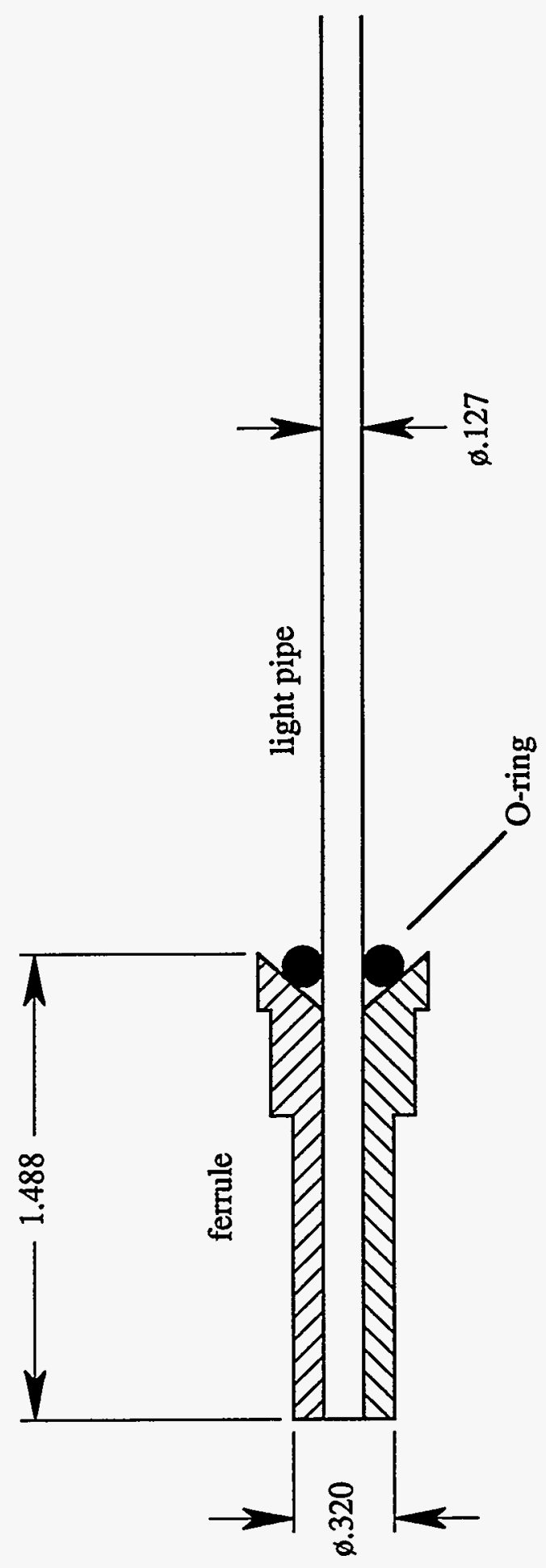

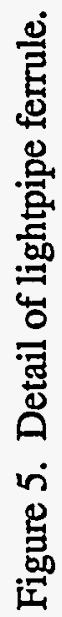




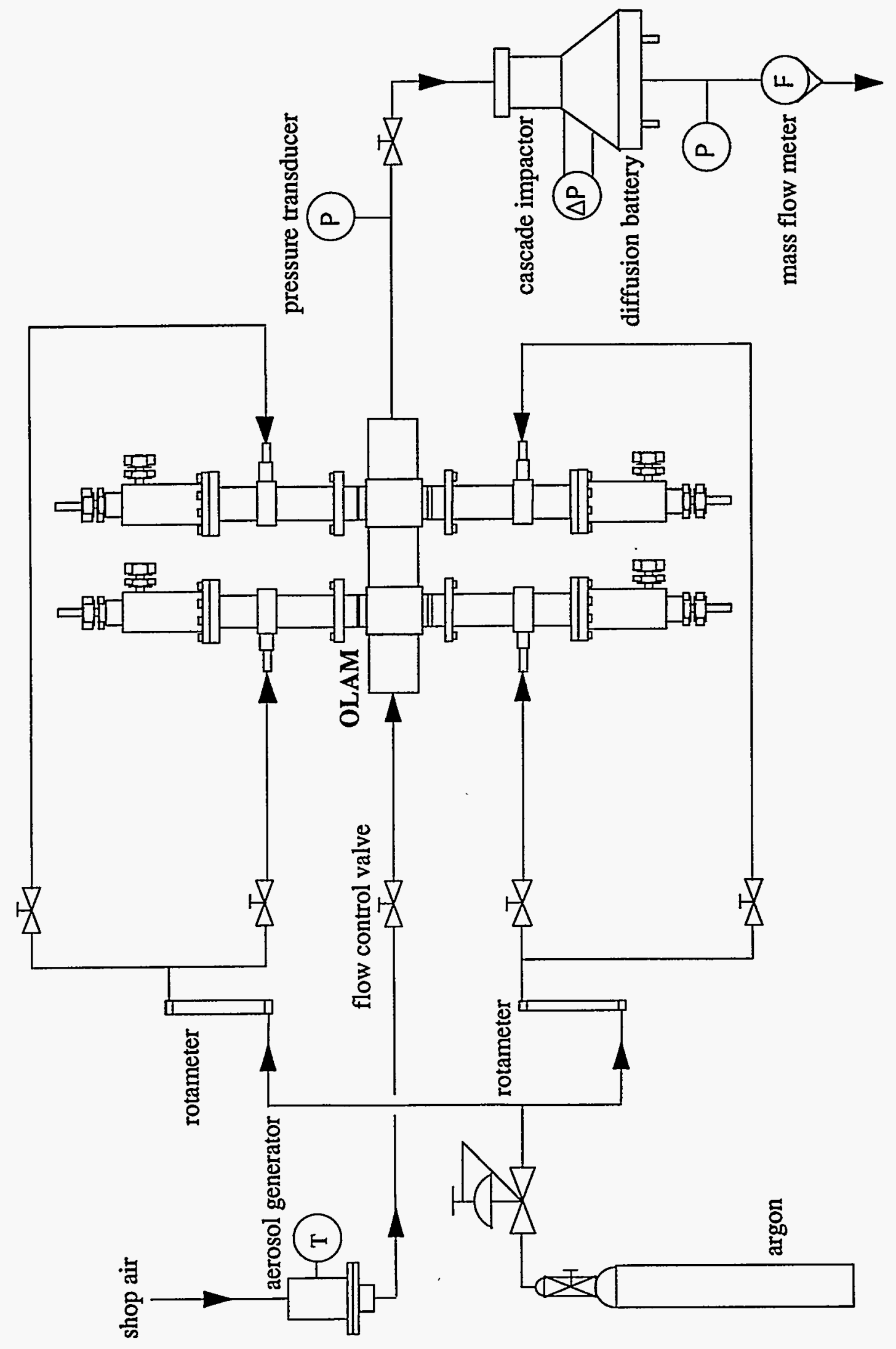

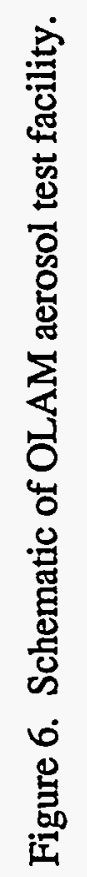




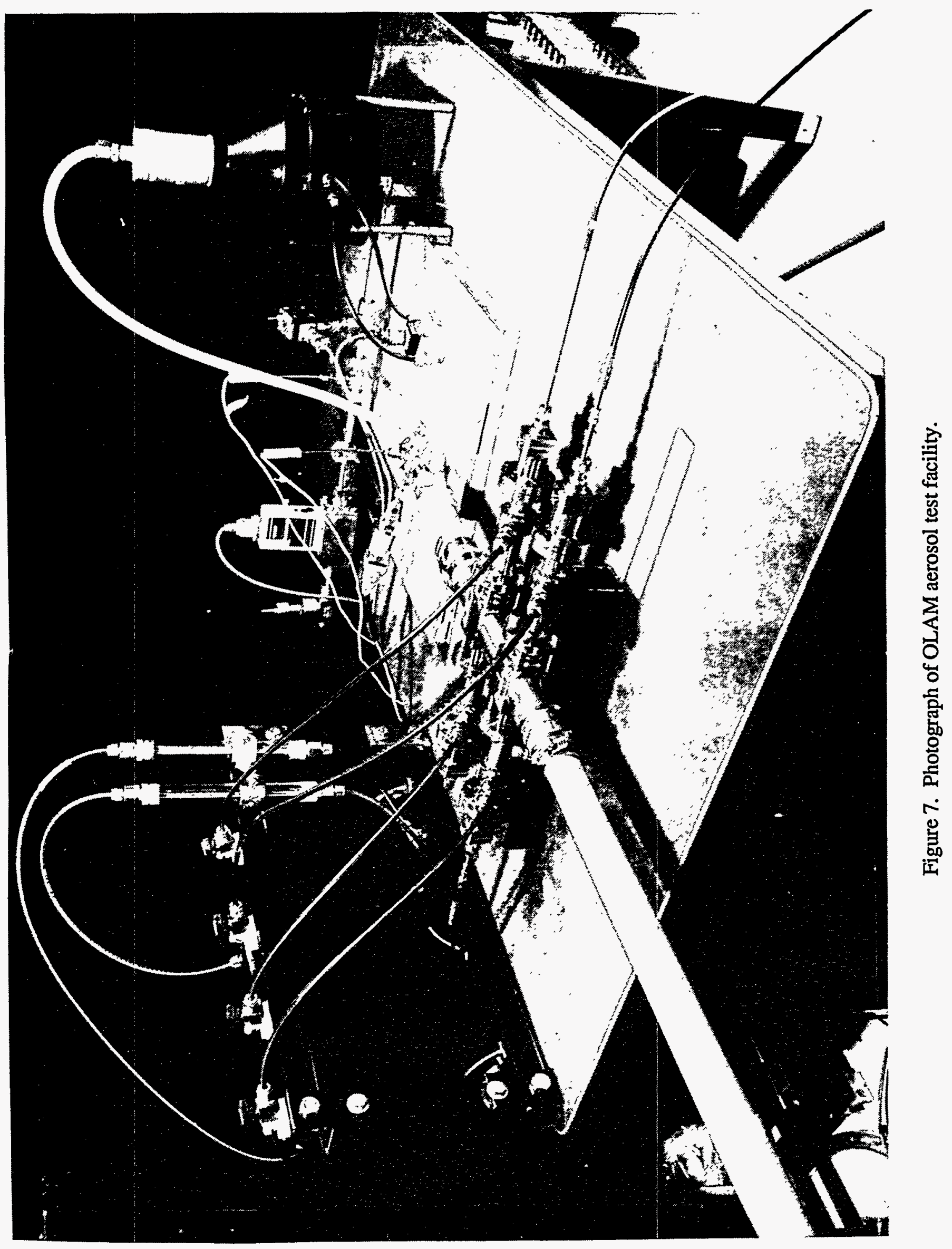




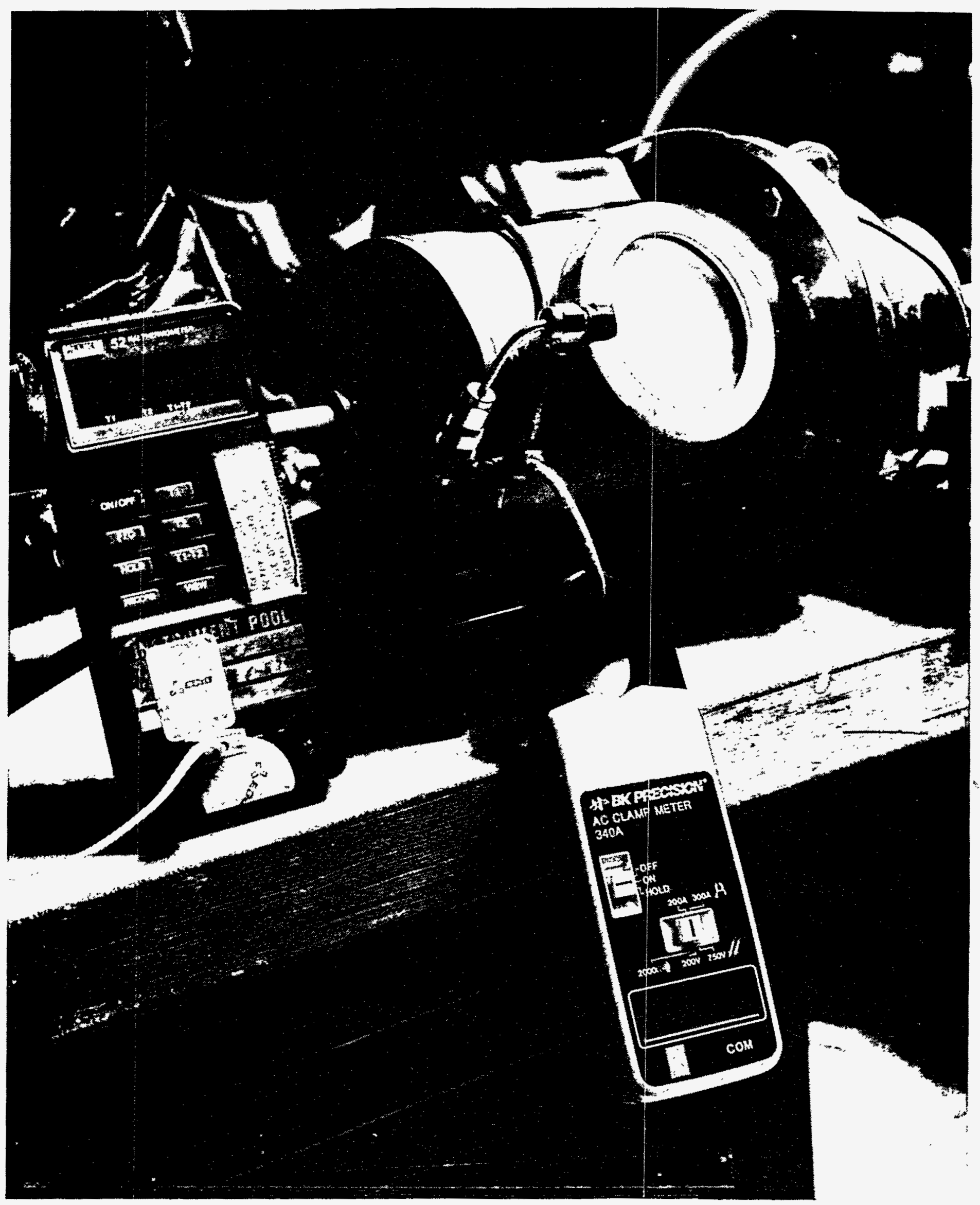

Figure 8. Photograph of aerosol generator chamber. 


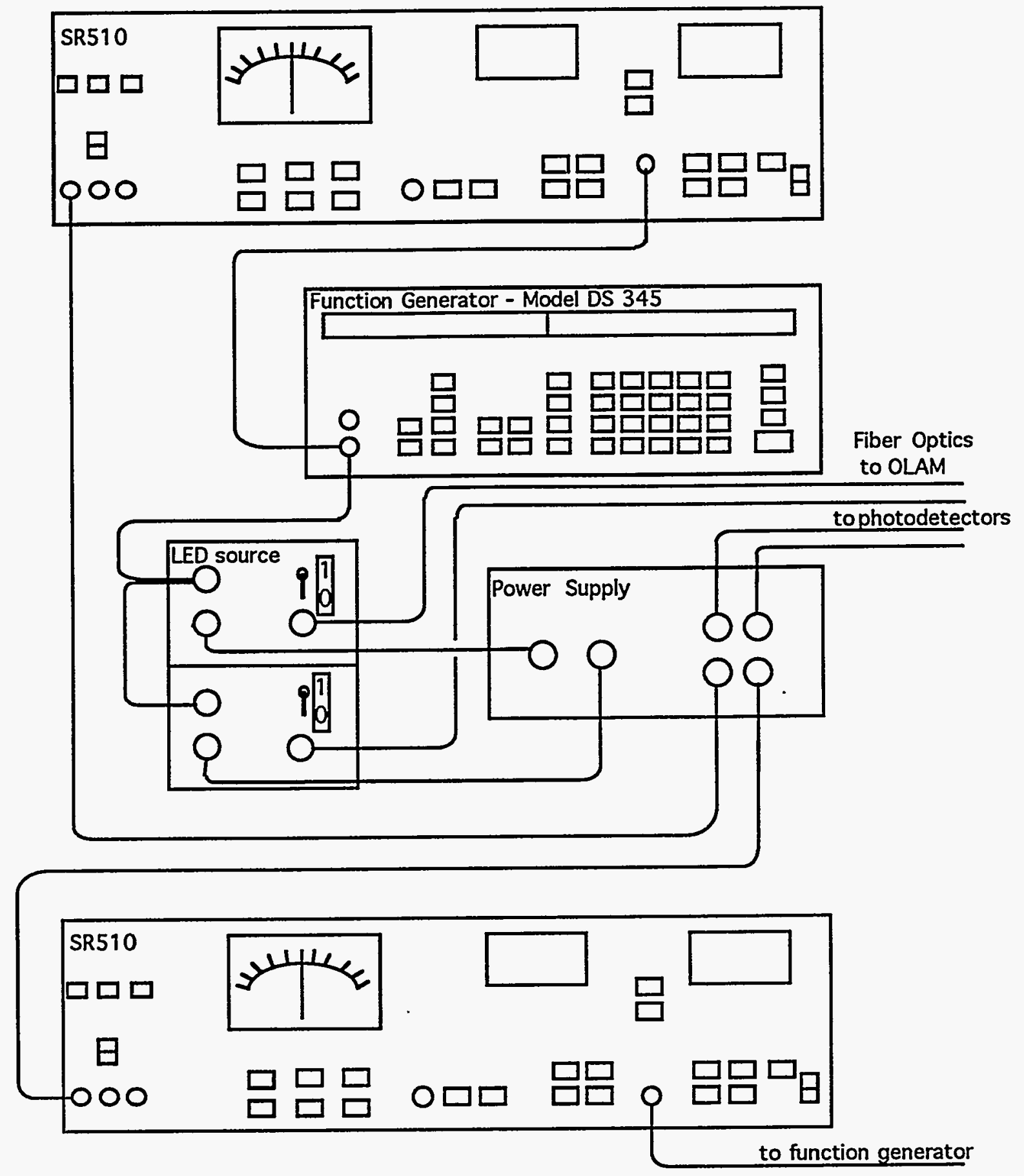

Figure 9. Schematic of OLAM electronics. 


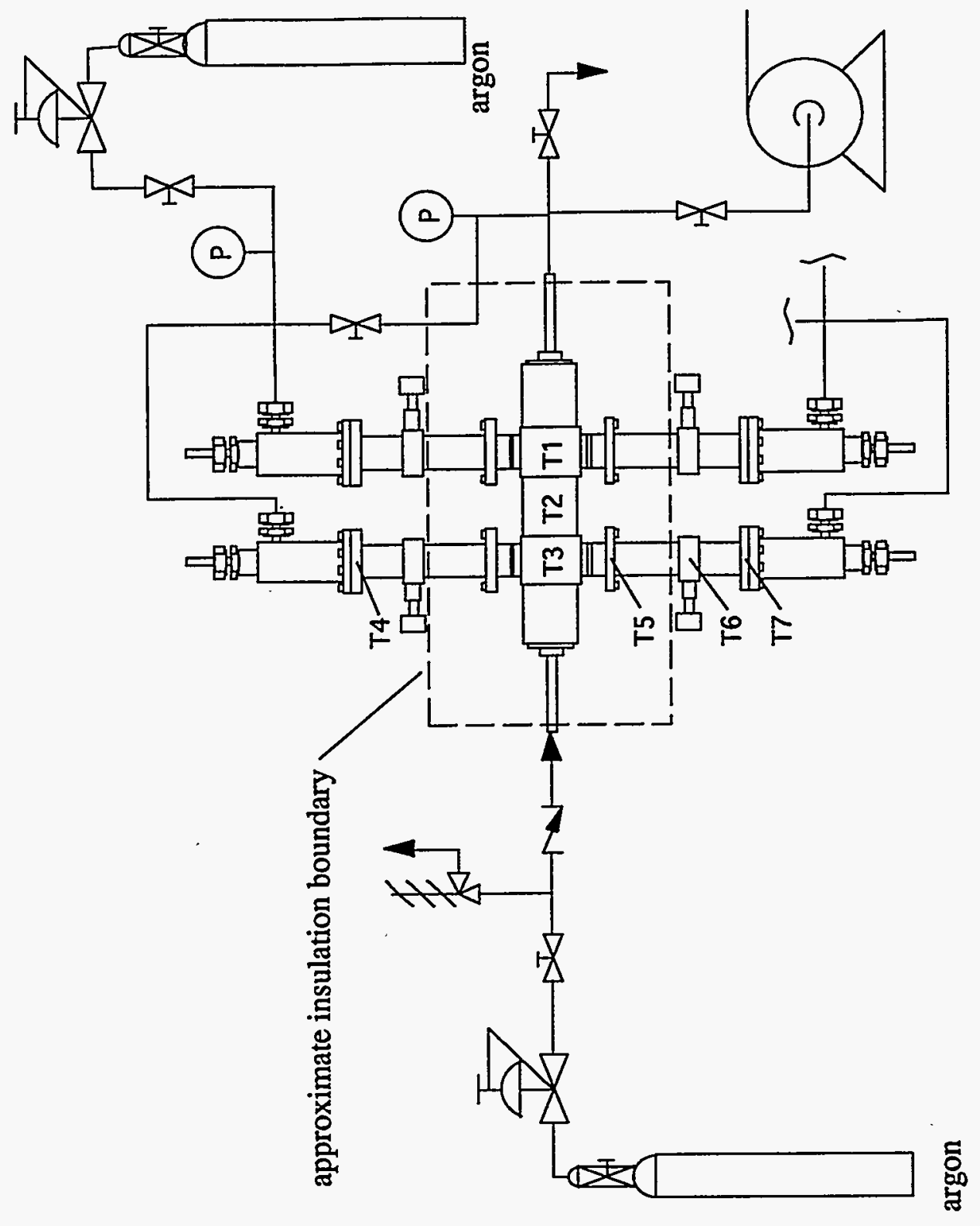

㻤 


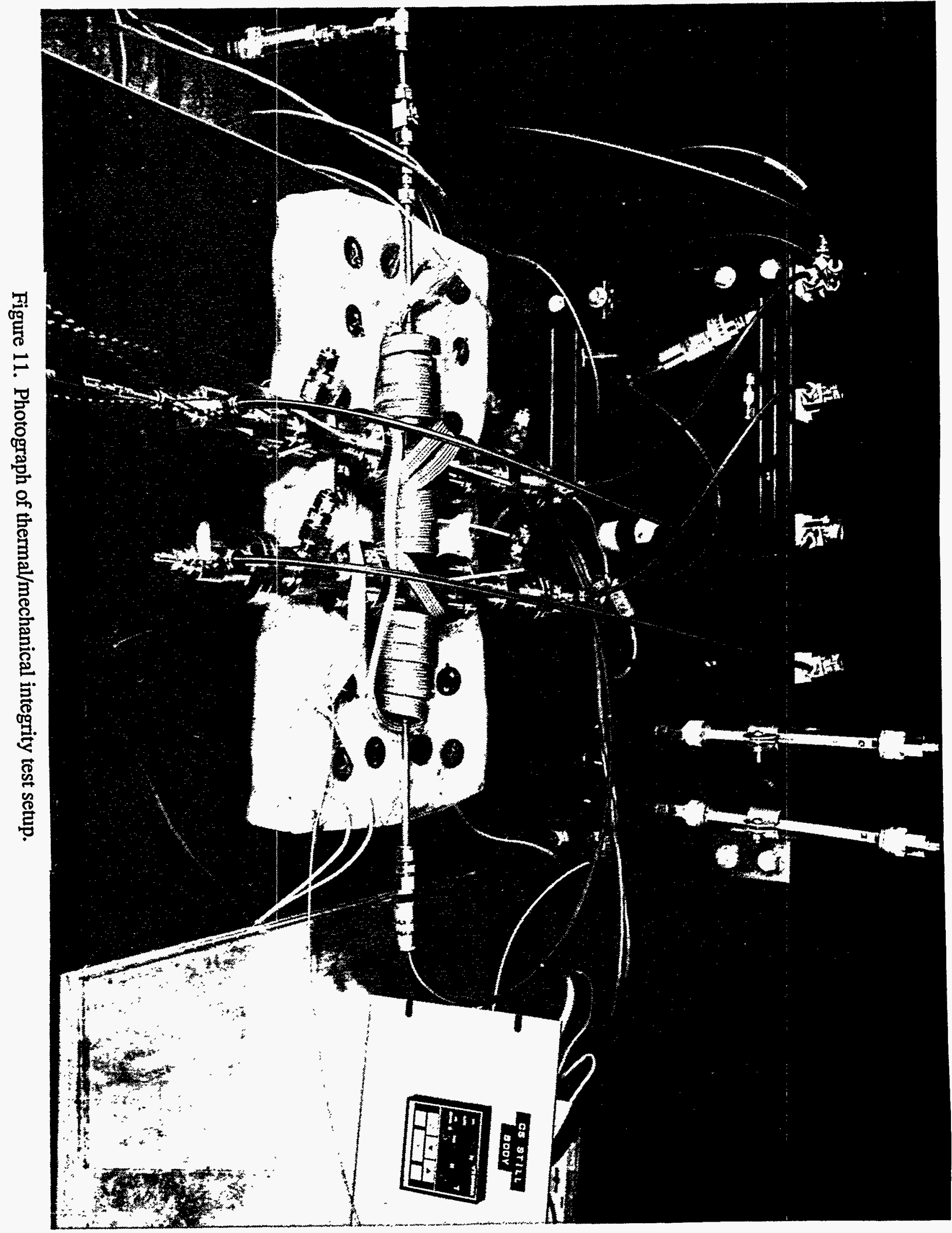




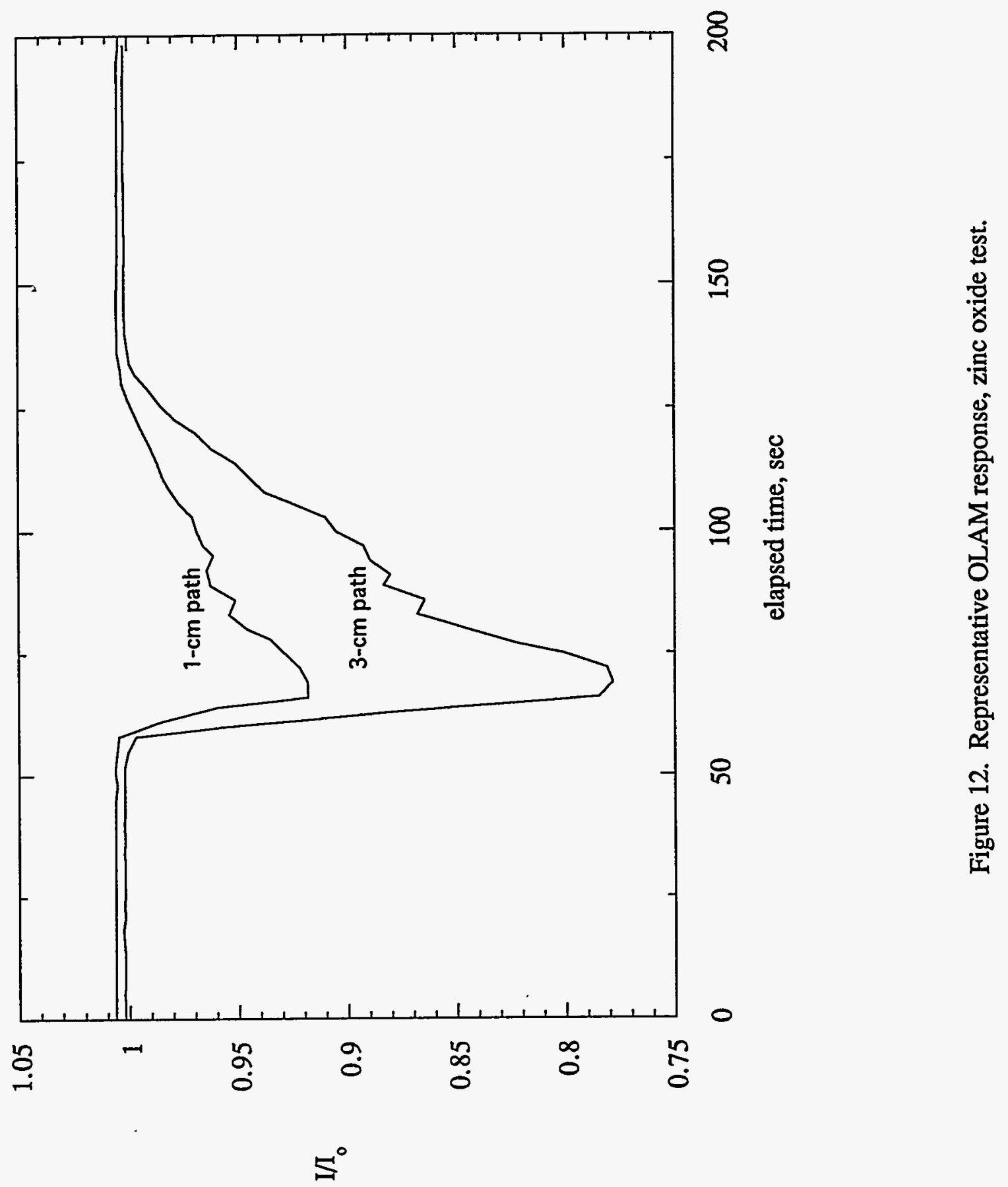




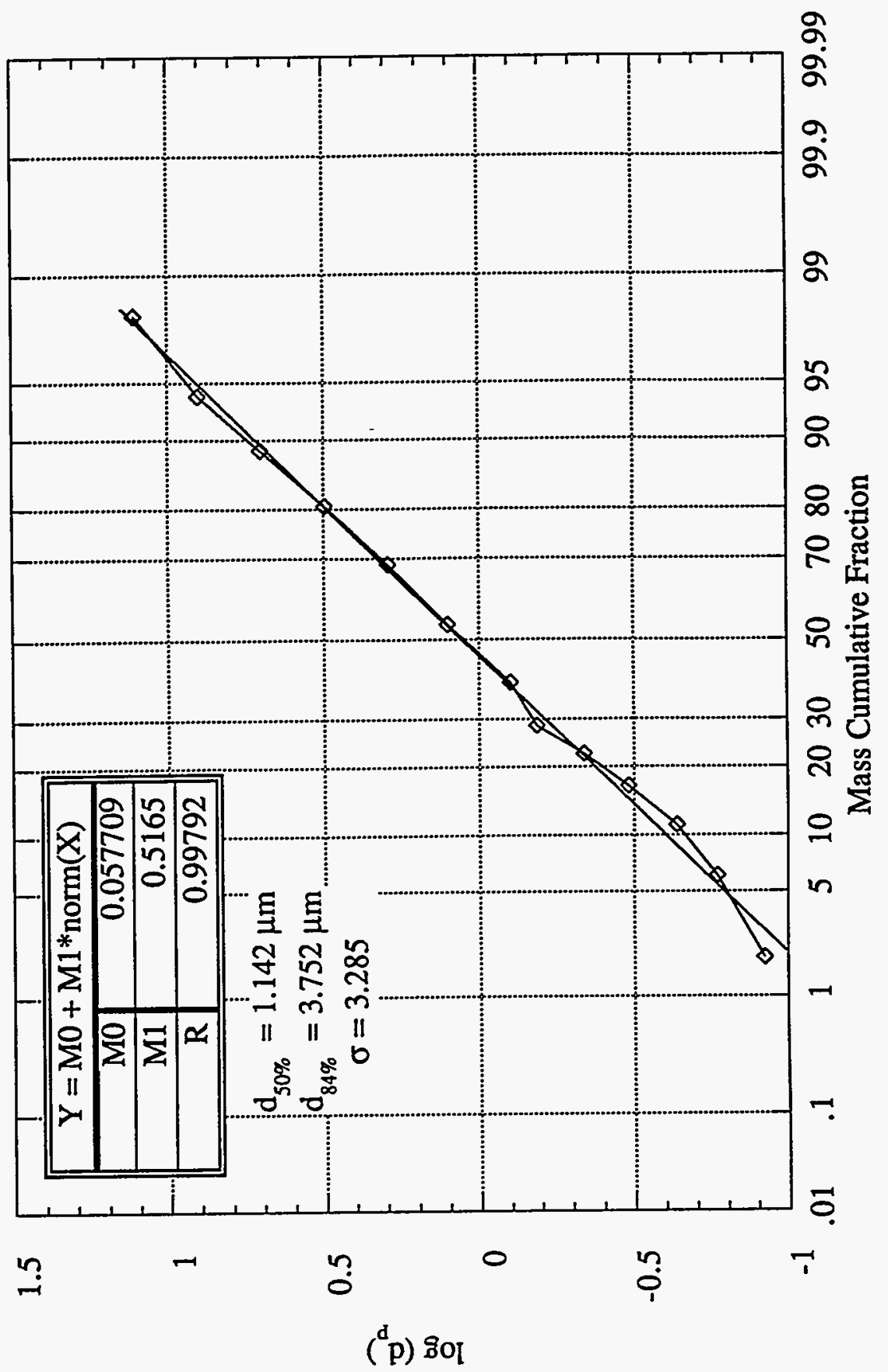

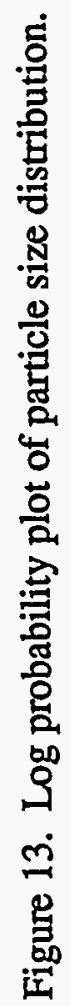




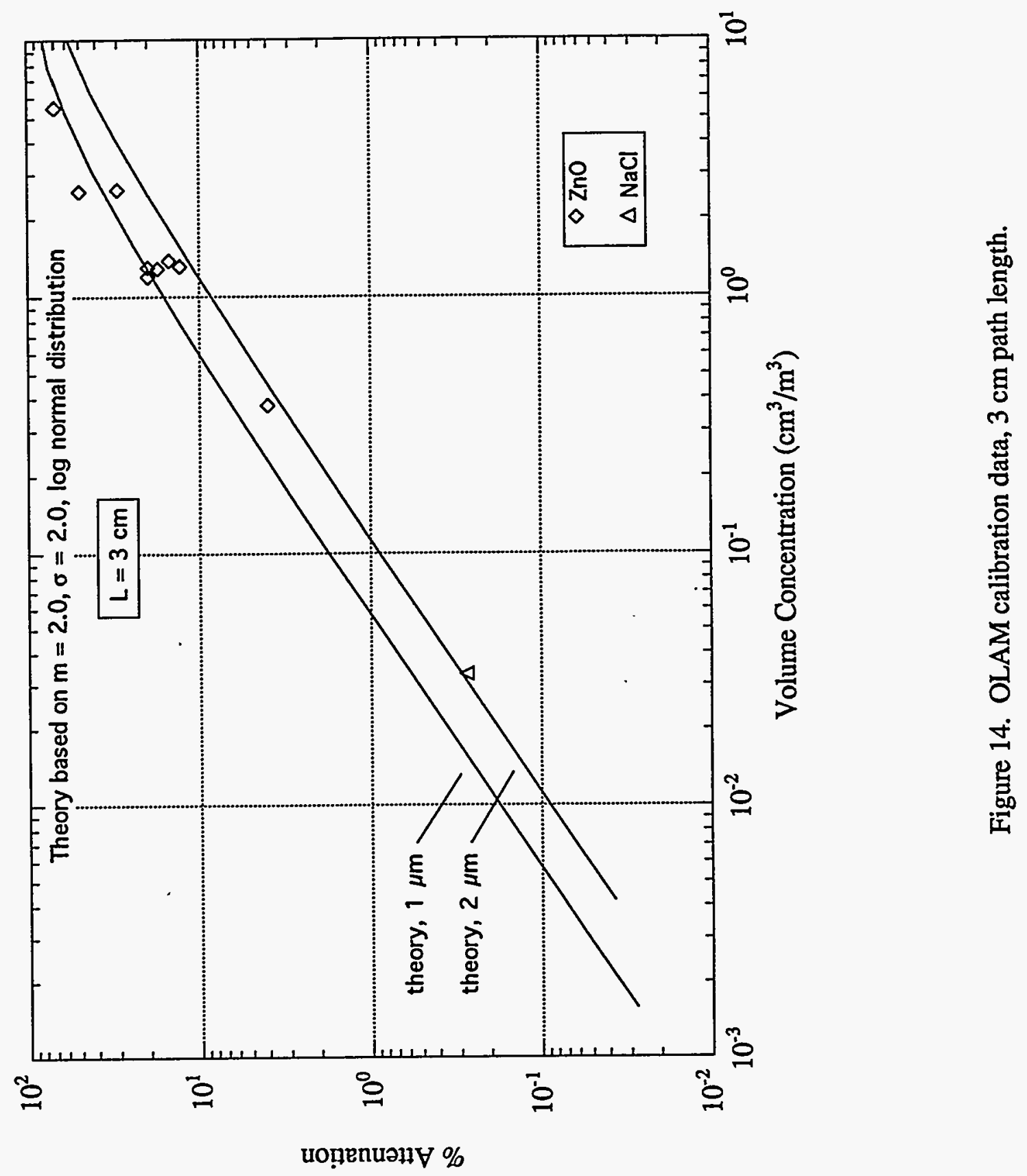




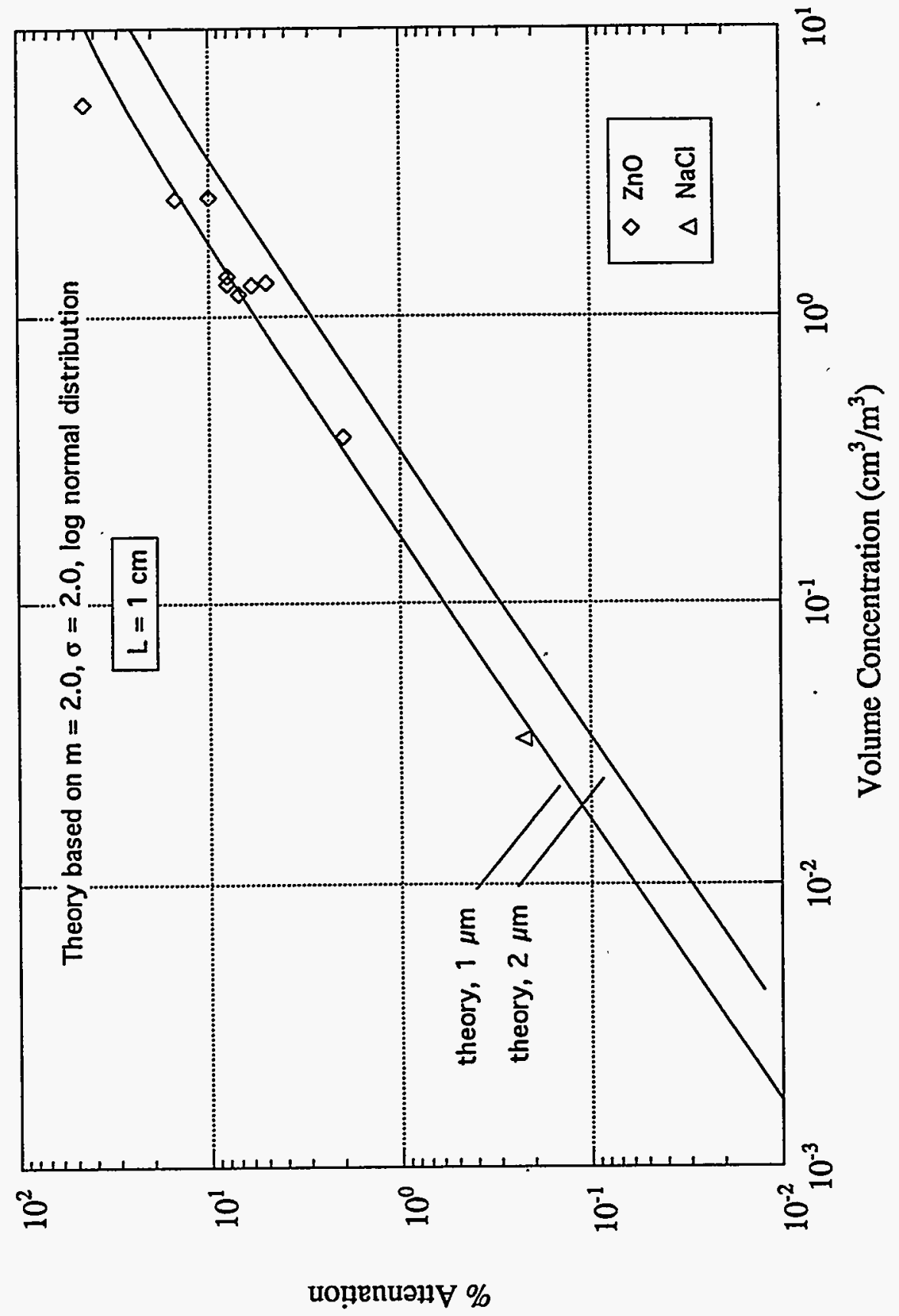

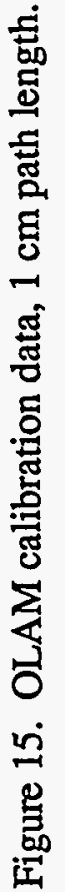




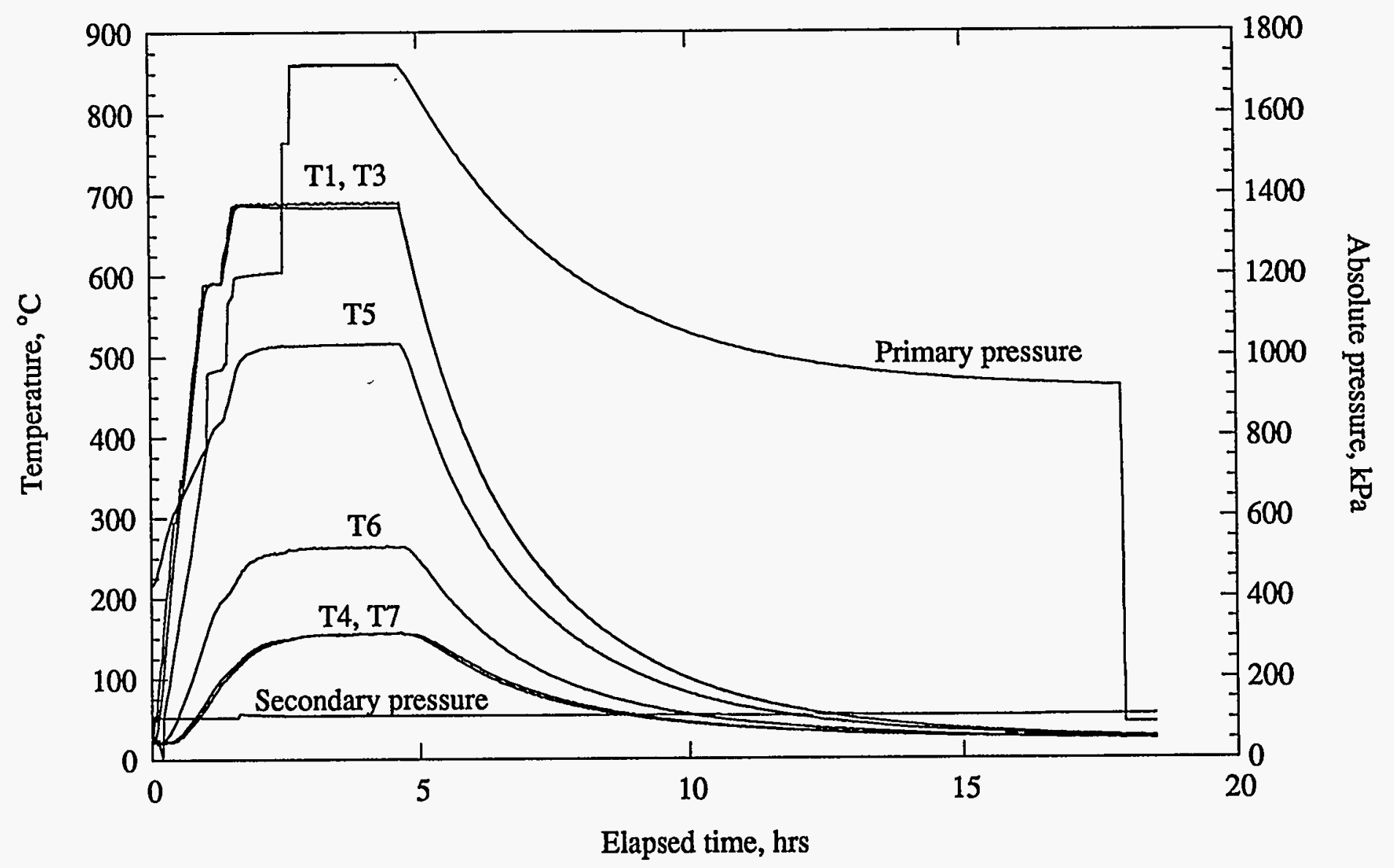

Figure 16. OLAM temperature and pressure histories, thermal/mechanical stability test. 


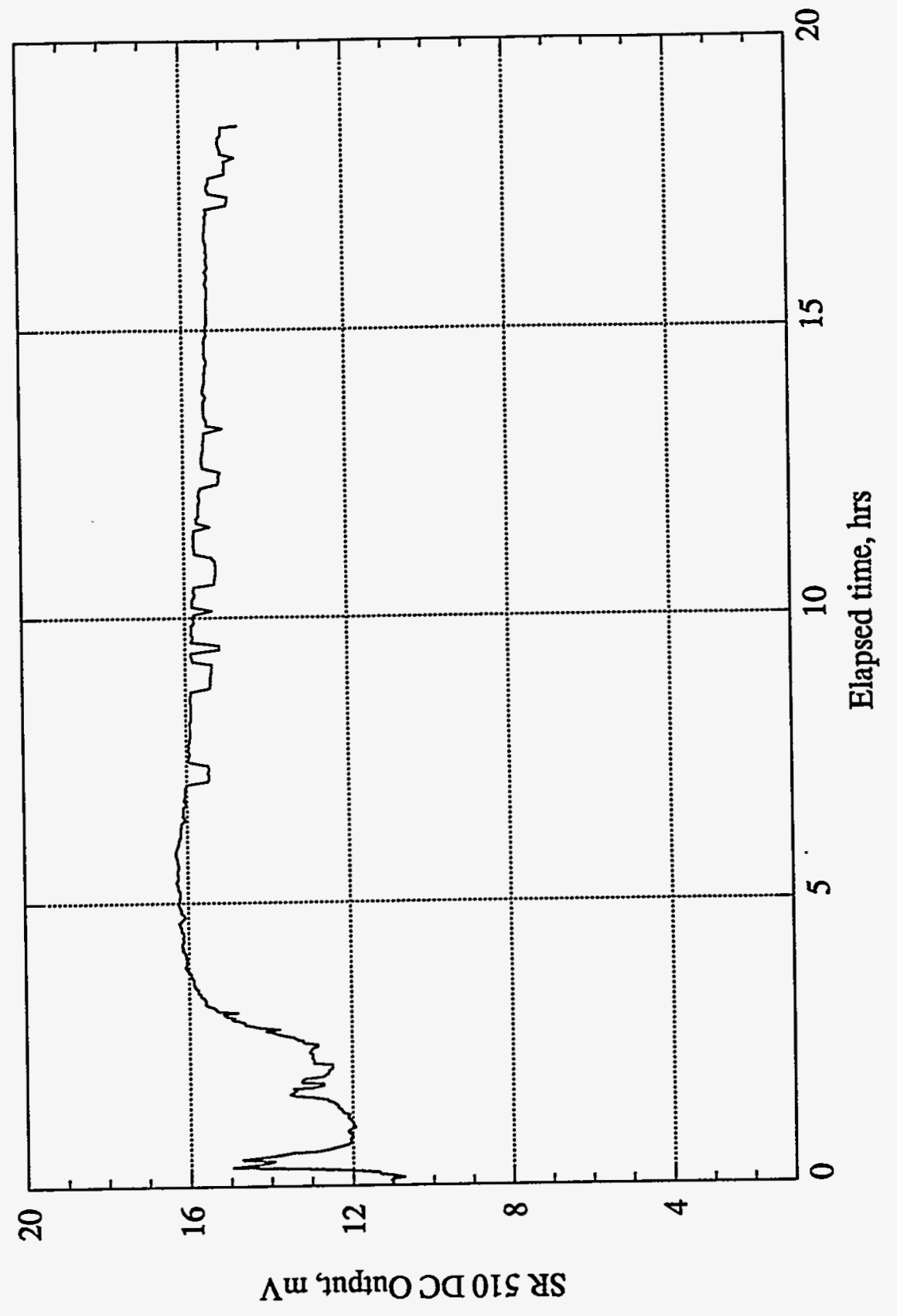

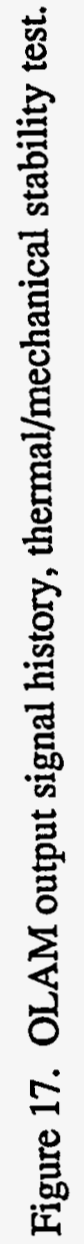

